\title{
Recent Advances in the Early Diagnosis of Oral Cancer: A Systematic Review
}

\author{
Nijampatnam PM. Pavani ${ }^{1,}{ }^{*}$, Priya Srinivas ${ }^{1}$, Nandita Rani Kothia ${ }^{1}$, Viswa Chaitanya Chandu ${ }^{1}$ \\ ${ }^{1}$ Department of Public Health Dentistry, Sibar Institute of Dental Sciences, Guntur, India
}

Corresponding Author: Nijampatnam PM. Pavani, MD, Assistant Professor, Department of Public Health Dentistry, Sibar Institute of Dental Sciences, Guntur, A.P, India. Email: madhupavani.dr@gmail.com

Received October 24, 2017; Accepted December 2, 2017; Online Published December 25, 2017

\begin{abstract}
Introduction: Oral cancer survival rates are strongly dependent upon the stage in which the diagnosis is being made. Patients diagnosed with oral cancer within the localized stage have a substantially greater chance of successful treatment, and there is a greater chance of morbidity if the patient is diagnosed with cancer in later stages. Successful early detection symbolizes one of the superlative techniques which would eventually increase the oral cancer survival rate and quality of life worldwide. This study aimed to illustrate and provide awareness of current trends and recent advances in early diagnostic tools of oral cancer and to differentiate the validity of diverse initial detection methods.

Methods: This research is a systematic review. The evaluation was confined to articles published in the past 15 years (i.e. 1999 2016). Searches were conducted both manually and electronically. A "manual exploration" was made by methodically examining key journals available in the library of the institution; documents and data were retrieved from the online databases PubMed and Google Scholar.

Results: In total, 19 articles were reviewed.

Conclusions: Oral cancer detection techniques can provide real-time diagnoses and are non-invasive. At present, large multicenter trials are necessary to determine the sensitivity and specificity of these individual and combined techniques and to evaluate and develop their ability to detect and manage potentially malignant and malicious oral lesions.

Keywords: Oral Cancer; Pre-Cancerous Lesions; Screening, Recent Advances; Sensitivity; Specificity; Early Diagnosis

Citation: Pavani NPM, Srinivas P, Kothia NR, Chandu VC. Recent advances in the early diagnosis of oral cancer: A systematic review. Int J Med Rev. 2017;4(4):119-125. doi: 10.29252/ijmr-040406.
\end{abstract}

\section{Introduction}

Oral cancer is the growth of malignant cells in the oral cavity. Sites affected by it include the lips, tongue, lining of the cheeks, floor of the mouth, hard and soft palates, gums, and teeth. Oral cancer is frequently discussed along with oropharyngeal cancer, which leads to throat cancer. ${ }^{1}$ It is the eighth most common cancer worldwide, and approximately 274,000 new cases are reported annually. ${ }^{2}$ Globally, oral cancer is ranked as the fourth most frequent cancer among men and the eighth most frequent cancer in women. ${ }^{3}$ Worldwide, the annual incidence of oral cancer is around 500,000, accounting for approximately $3 \%$ of all malignancies. Thus, this disease creates a substantial worldwide health burden. The incidence of oral cancer differs from one region to another in the world. It appears that geographic location has no relationship with it; rather, it is a problem of oral habits among the people of certain countries. Oral cancer ranks first among the three deadliest cancers in South Central Asia. Recent epidemiologic data displays sharp surges in the incidence of oral cancer reported in European countries and, to a lesser extent, in the USA. In some countries like Sri Lanka, India, Pakistan, and Bangladesh, oral cancer is the most common type of malignancy. In India, it accounts for more than $50 \%$ of all malignancies recorded. Specific oral habits, such as chewing betel and other similar habits, are triggering the high incidence rate in the above-mentioned countries. Oral cancer is largely related to lifestyle. Major lifestyle factors of this type of cancer are the misuse of tobacco and the misuse of alcohol. In addition to smoking, the use of smokeless tobacco has been strongly associated with oral cancer. ${ }^{4}$ About $40 \%$ of head and neck malignancies are known to be squamous cell carcinomas arising in the oral cavity. ${ }^{5}$ The five-year survival capacity of oral cancer varies from $81 \%$ for patients with localized disease to $42 \%$ for those with regional disease and to $17 \%$ if distant metastases are present. ${ }^{3}$ Generally, patients diagnosed in the late stage have a $50 \%$ chance of survival,

Copyright (C) 2017 The Author(s). This is an open-access article distributed under the terms of the Creative Commons Attribution License (http://creativecommons.org/licenses/by/4.0), which permits unrestricted use, distribution, and reproduction in any medium, provided the original work is properly cited. 
i.e. less than five years. This rate has remained lamentably low and relatively constant during the last few decades. ${ }^{6}$ This review flows with an aim and objectives as given below.

\section{Objectives}

- To illustrate and become acquainted with the trends in recent advances in early diagnostic aids of oral cancer

- To recognize the validity of different early detection methods;

- To outline the recommendations of the researchers on efficient early diagnostic techniques in clinics and field work.

\section{Methods}

Search Strategy and Eligibility Criteria

This systematic review was conducted on recent advances in diagnosing oral cancer. For this, a thorough literature search was carried out both manually and electronically. The databases PubMed and Google Scholar were searched using MeSH entry terms mixed with Boolean phrases 'AND' or 'OR'. Articles included were confined to the past 15 years. Duplications were discarded. Apart from the online search, articles were also collected from related journals available in the institutional library. Clear representation of the included literature and summarization of the available insights regarding the topic of interest were done following the Preferred Reporting Items for Systematic Reviews and Meta-analyses (PRISMA) checklist.

Data Collection

The basic search resulted in a total of 1,283 articles, which included mainly original articles, overviews, and reviews. Articles other than original research on human participants were excluded from the study. Articles not relevant to the topic of interest or objectives of the study were excluded.

Data Extraction and Analysis

The number of articles included at each stage based on the eligibility criteria are shown in Figure 1. After completing the search, the selected documents were summarized and categorized based on the topic and its implications. Finally, the selected articles were categorized based on indexation (Table 1).

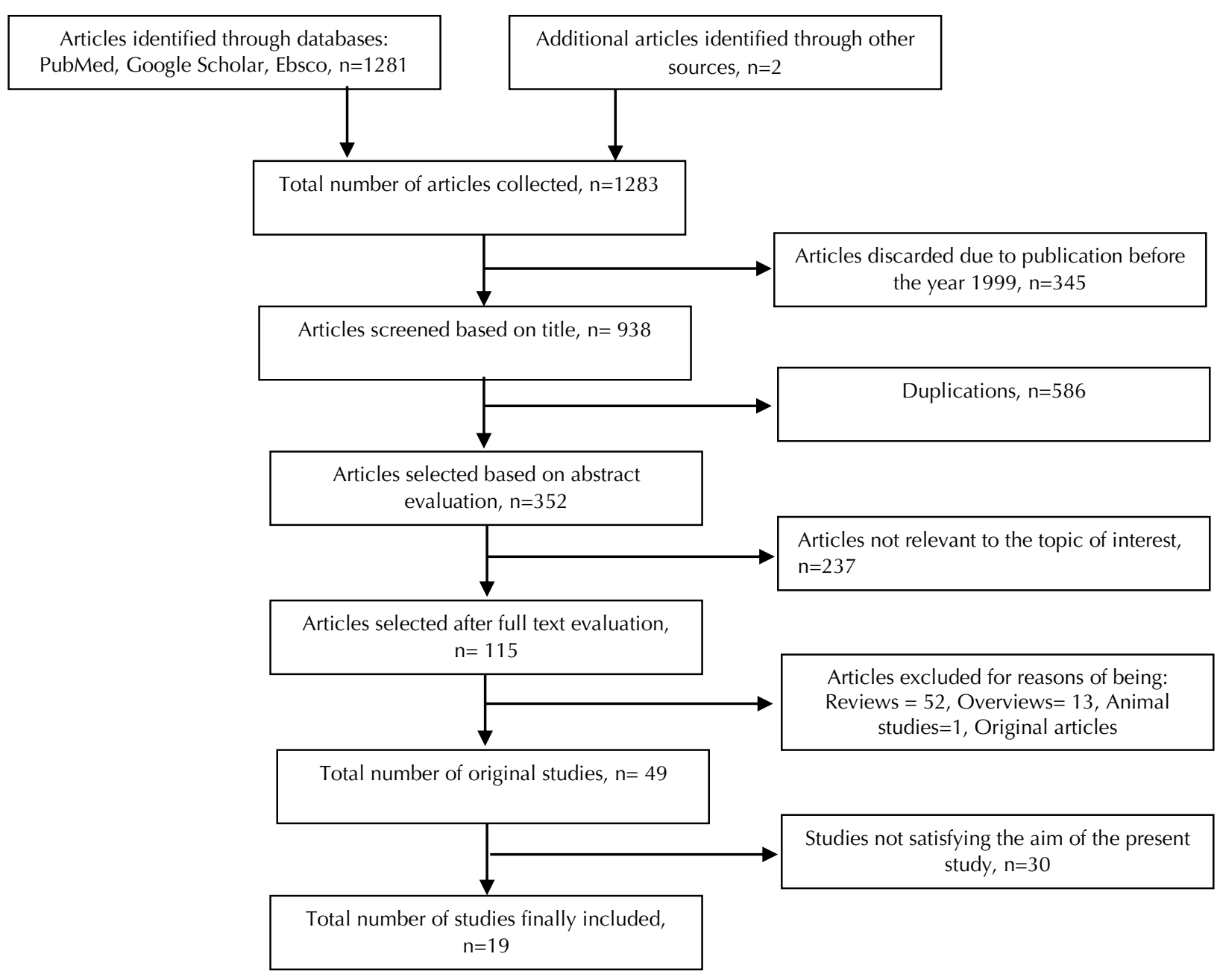

Figure 1. Flow chart of the study 


\section{Results}

Finally, the total number of articles included in the study was 19. Table 1 shows that most of the articles included in the study were published in PubMed-indexed journals. Publications related to the topic of interest surged in the year 2011 (Figure 2). Table 2 shows the country wise distribution of the articles. As can be seen, the maximum number of articles was Indian-based. Table 3 shows various early diagnostic tools pertaining to oral cancer given by different authors, their comparison with the gold standard biopsy, the types of lesions that were included in the studies, sensitivity, specificity, positive predictive values, negative predictive values, and accuracy.

Table 1. Distribution of articles based on indexation

\begin{tabular}{lc}
\hline Indexation & No. of Articles \\
\hline PubMed & 17 \\
Non-PubMed & 02 \\
\hline Total & 19 \\
\hline
\end{tabular}

\section{Discussion}

- Malignancy: Inclining to become progressively worse and to result in death; having the properties of anaplasia, invasiveness, and metastasis. ${ }^{7}$

- Pre-malignancy: Morphologically-altered tissue in which cancer is more likely to develop than its apparently normal counter-part1, or a generalized disturbance or a disease state which predisposes the patient to the development of a neoplasm at a particular site. ${ }^{8}$

- Sensitivity: The ability of a test to correctly identify all those who have the disease, i.e. true positives. A sensitivity of $90 \%$ means that $90 \%$ of the diseased persons screened by the test will give "true positive" results, and the remaining $10 \%$ will give "false negative" results. 9 "

- Specificity: The ability of a test to correctly identify all those who do NOT have the disease, i.e. true negatives. A specificity of $90 \%$ means that $90 \%$ of the non-diseased persons will give "true negative" results, and $10 \%$ of nondiseased people screened by the test will be wrongly classified as "diseased". 9

- Accuracy: The extent to which the test accurately measures what it purports to measure. In other words, validity explains the ability of a test to separate or distinguish those who have the disease from those who do not28.

- Positive predictive value: Probability of patients having the disease in question when the test result is positive. ${ }^{9}$

- Negative predictive value: Probability of patients not having the disease in question when the test result is negative. ${ }^{9}$

Intervallic clinical examination of the oral cavity is the mainstay for early detection of oral cancer as it has been shown to reduce mortality from oral cancer by $32 \%$ in high-risk individuals. ${ }^{10}$ With the aim of improving the efficiency of oral cancer diagnoses, advanced techniques are being developed to complement clinical examination

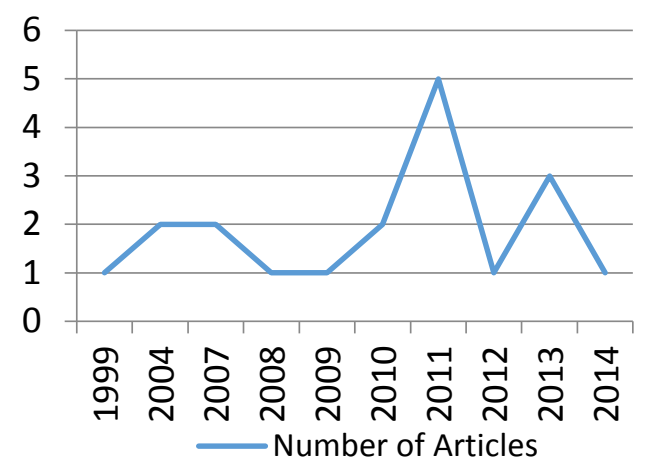

Figure 2. Year wise distribution of articles

Table 2. Country wise distribution of articles

\begin{tabular}{|lc|}
\hline Countries & No. of Articles \\
\hline INDIA & 08 \\
U.K. & 03 \\
U.S.A. & 01 \\
Others & 07 \\
Total & 19 \\
\hline
\end{tabular}

and facilitate the identification of carcinomas in initial stages. Progression in the field of oral cancer research has led to the development of diagnostic tools at both the clinical and molecular level for the early recognition of oral cancer. ${ }^{11}$ An early recognition of these cancers helps the provision of better and faster treatment to improve prognoses to some degree. The available advanced diagnostic adjuncts are helpful tools for the early diagnosis of oral cancer. ${ }^{12}$

Oral Cancer Survival Rates

Oral cancer survival rates are strongly reliant on the stage at diagnosis. Patients diagnosed with oral cancer at a localized stage have a considerably greater chance of successful treatment and less treatment-associated morbidity than those diagnosed at a late stage. Improving early recognition is one of the best ways to improve survival rates and quality of life for oral cancer patients worldwide. In developing countries, oral cancer patients tend to be diagnosed at a later stage than that in developed countries. Thus, there remains a vital need to improve early detection of oral cancer and its precursors. The contemporary goal of the International Agency for Research on Cancer, American Cancer Society, and the WHO is to reduce the predicted 15 million cancer cases by a third by diagnosing and treating these cancers at their pre-neoplastic levels. Oral cancer is an ideal choice for this strategy, because the oral cavity delivers easy access for clinical scrutiny, and development of oral cancer is preceded by perceptible mucosal changes. However, only $40 \%$ of oral cancers are presently diagnosed as localized disease, which is the same rate as that of colon cancers. ${ }^{2}$ Despite recent diagnostic and therapeutic advances, the 5-year survival rate for oral cancer has persisted at less than $50 \%$ over the last 50 years owing to the following reasons: first, the bulk of oral cancer cases, i.e. around $60 \%$ of cases, were noticed in 
their advanced stages (III and IV). Secondly, the maximum number of oral cancer cases runs the risk of transforming into secondary tumors ("field cancerization phenomenon") compared with other cancers.

\begin{tabular}{|c|c|c|c|c|c|c|c|c|c|c|}
\hline $\begin{array}{l}\text { S. } \\
\text { No }\end{array}$ & Author & Year & $\begin{array}{c}\text { Early diagnostic tool } \\
\text { used }\end{array}$ & Gold standard & Type of lesion & $\begin{array}{c}\mathrm{Se} \\
(\%)\end{array}$ & Sp (\%) & $\begin{array}{l}\text { PPV } \\
(\%)\end{array}$ & $\begin{array}{l}\text { NPV } \\
(\%)\end{array}$ & $\begin{array}{l}\text { Accuracy } \\
(\%)\end{array}$ \\
\hline 1 & James J. Sciudda & 1999 & $\begin{array}{l}\text { Oral CDx biopsy (Brush } \\
\text { biopsy) }\end{array}$ & Scalpel biopsy & $\begin{array}{l}\text { Precancerous } \\
\text { and cancerous }\end{array}$ & 100 & 92.9 & - & - & - \\
\hline 2 & $\begin{array}{c}\text { Christian } \\
\text { Scheifele et al. }{ }^{14}\end{array}$ & 2004 & $\begin{array}{l}\text { Oral CDx biopsy (Brush } \\
\text { biopsy) }\end{array}$ & Scalpel biopsy & $\begin{array}{l}\text { Leukolakia, } \\
\text { lichen planus, } \\
\text { OSCC }\end{array}$ & 92.3 & 94.3 & - & - & - \\
\hline \multirow[t]{2}{*}{3} & $\begin{array}{l}\text { S. Ram \& C. H. } \\
\text { Siar }^{15}\end{array}$ & 2004 & ViziLite & Biopsy & $\begin{array}{l}\text { Premalignant } \\
\text { epithelial }\end{array}$ & 100 & 14.2 & - & - & 80.6 \\
\hline & & & Toluidine Blue & $\begin{array}{l}\text { Histological } \\
\text { examination }\end{array}$ & Malignant & 70.3 & 25 & & & 64.5 \\
\hline 4 & 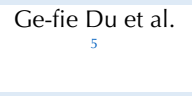 & 2007 & Rose Bengal stain & $\begin{array}{l}\text { Histological } \\
\text { examination } \\
\text { Scalpel biopsy }\end{array}$ & $\begin{array}{l}\text { Precancerous } \\
\text { and cancerous }\end{array}$ & 93.9 & 73.7 & 55.4 & 97.2 & - \\
\hline 5 & $\begin{array}{l}\text { Ya-wei Chen et } \\
\text { al. }{ }^{10}\end{array}$ & 2007 & Methylene Blue & $\begin{array}{l}\text { Histological } \\
\text { examination }\end{array}$ & $\begin{array}{l}\text { Precancerous } \\
\text { and cancerous }\end{array}$ & 90 & 69 & 74 & 87 & - \\
\hline 6 & $\begin{array}{c}\text { Kanokporn } \\
\text { Bhalang et al. }{ }^{16}\end{array}$ & 2008 & 5 acetic acid & Incisional biopsy & Precancerous & 83.33 & 84.21 & - & - & 83.64 \\
\hline \multirow[t]{2}{*}{7} & E. Allegra et al. & 2009 & Clinical examination & Punch biopsy & Premalignant & 53 & 80 & 84.2 & 46.1 & - \\
\hline & & & Toluidine blue & - & malignant & 96.2 & 77.7 & 86.6 & 93.3 & - \\
\hline 8 & $\begin{array}{c}\text { Kamarthi } \\
\text { Nagaraju et al. } \\
18\end{array}$ & 2010 & $\begin{array}{l}\text { Lugol's lodine when } \\
\text { used consecutively with } \\
\text { Toluidine blue }\end{array}$ & Biopsy & $\begin{array}{l}\text { Premalignant } \\
\text { and malignant }\end{array}$ & 92.7 & 60 & 96 & 43 & 90 \\
\hline \multirow[t]{2}{*}{9} & $\begin{array}{l}\text { K. H. Awan et } \\
\text { al. }{ }^{19}\end{array}$ & 2010 & ViziLite & Biopsy & Premalignant & 77.1 & 26.8 & 56.8 & 48.4 & - \\
\hline & & & - & - & malignant & 77.3 & 27.8 & 39.5 & 66.7 & - \\
\hline 10 & $\begin{array}{l}\text { K. H. Awan et } \\
\text { al. }{ }^{20}\end{array}$ & 2011 & VELscope & Surgical biopsy & $\begin{array}{l}\text { Premalignant } \\
\text { and malignant }\end{array}$ & 84.1 & 15.3 & - & - & - \\
\hline 11 & Ravi Mehrota ${ }^{21}$ & 2011 & $\begin{array}{c}\text { Oral brush biopsy with } \\
\text { computer assisted } \\
\text { analysis }\end{array}$ & Scalpel biopsy & $\begin{array}{l}\text { Precancerous } \\
\text { and cancerous }\end{array}$ & 96.3 & $\begin{array}{c}\text { Positive = } \\
100, \\
\text { Atypical } \\
=90.4\end{array}$ & 84 & 98 & - \\
\hline 12 & $\begin{array}{l}\text { Palomacancela } \\
\text { Rodriguez et al. }\end{array}$ & 2011 & Toluidine Blue & $\begin{array}{l}\text { Histopathological } \\
\text { examination }\end{array}$ & $\begin{array}{l}\text { Malignant and } \\
\text { dysplastic }\end{array}$ & 65.5 & 73.3 & 35.2 & 90.6 & - \\
\hline 13 & $\begin{array}{l}\text { Majeed Rana et } \\
\text { al. }{ }^{23}\end{array}$ & 2011 & $\begin{array}{l}\text { VELscope along with } \\
\text { white light }\end{array}$ & Biopsy & Premalignant & 100 & 74 & - & - & - \\
\hline 14 & Juhi Upadhyay & 2011 & Toluidine Blue & Biopsy & $\begin{array}{c}\text { Potentially } \\
\text { malignant }\end{array}$ & 73.9 & 30 & 54.83 & 50 & - \\
\hline \multirow[t]{2}{*}{15} & Shweta Ujaoney $_{25}$ & 2012 & Chemiluminescence & Biopsy & $\begin{array}{c}\text { High risk } \\
\text { precancerous }\end{array}$ & 1.00 & 0.01 & - & - & - \\
\hline & & & Toluidine Blue & - & oral lesions & 0.59 & 0.79 & & & \\
\hline 16 & $\begin{array}{c}\text { Akthar Riaz et } \\
\text { al. }{ }^{26}\end{array}$ & 2013 & Methylene Blue & Biopsy & $\begin{array}{l}\text { Oral } \\
\text { precancers } \\
\text { and OSCC }\end{array}$ & 91.4 & 66.6 & 97.7 & 33 & 90 \\
\hline 17 & $\begin{array}{l}\text { Shyam Prasad } \\
\text { Reddy et al. }{ }^{27}\end{array}$ & 2013 & $\begin{array}{l}\text { Non-focal microscopy } \\
\text { with Acridine Orange } \\
\text { (AO) staining for } \\
\text { cytological diagnosis }\end{array}$ & Exfoliative cytology & $\begin{array}{c}\text { Diagnosed } \\
\text { and suspected } \\
\text { OSCC }\end{array}$ & 93 & 93 & - & - & - \\
\hline \multirow[t]{6}{*}{18} & $\underset{28}{\text { Sapna }} \underset{28}{\text { M. et al. }}$ & 2013 & Toluidine blue(TB) & Wedge biopsy & Malignant & 92 & 82 & 93 & 79 & \\
\hline & & & - & - & Premalignant & 61 & 80 & 91 & 36 & \\
\hline & & & Brush biopsy(BB) & - & Malignant & 91 & 91 & 96 & 79 & - \\
\hline & & & - & - & Premalignant & 83 & 90 & 96.7 & 60 & - \\
\hline & & & Combined & - & Malignant & 93 & 95 & 99 & 84 & - \\
\hline & & & & - & Premalignant & 88 & 90 & 96 & 69 & - \\
\hline \multirow[t]{2}{*}{19} & $\begin{array}{l}\text { Neha Vashisht } \\
\text { et al. }{ }^{29}\end{array}$ & 2014 & $\begin{array}{l}\text { ViziLite Toluidine Blue } \\
\text { (TB) }\end{array}$ & Incisional biopsy & Premalignant & 95.45 & 84.6 & & & \\
\hline & & & & & malignant & 86.63 & 76.9 & & & \\
\hline
\end{tabular}

The 5-year recurrence-free survival rate in oral cancer patients is $80 \%$ for those diagnosed in stage I and only $20 \%$ for those diagnosed in stage IV. Moreover, diagnosis at early stages of oral cancer greatly reduces treatmentrelated morbidity and improves the long-term survival rate. Patients with a history of oral cancers are at risk of developing secondary tumors at a rate of $3.7 \%$ per year. Because of "field cancerization," one fourth of all oral cancer-related deaths are caused by secondary tumors. Hence, patients who are effectively treated for oral cancer should be closely monitored, preferably using a noninvasive diagnostic test. The lack of an early-stage diagnosis of oral cancer or diagnosis at the pre-neoplastic level impedes increasing survival rates in oral squamous cell carcinoma patients. However, poor detection rates were registered during routine clinical examination by general dentists.

In day-to-day clinical practice, dental and medical practitioners repeatedly encounter a wide variety of oral mucosal lesions. Oral cancer is generally preceded by 
some benign lesions existing for a varying length of time. Tobacco users with pre-cancerous lesions run the risk of developing oral cancer at a rate 69 times greater than those who do not have pre-cancer. The recognition and management of pre-cancer, therefore, set up a vital cancer control measure. Currently, the most efficient way of battling oral cancer is by early diagnosis followed by suitable treatment. The clinician's dilemma is how to differentiate cancerous lesions from a swarm of other illdefined lesions that also occur in the oral cavity. The majority of oral lesions are benign, but these lesions may have an appearance that may be easily confused with malignant lesions, and some are considered premalignant, because they have been statistically connected with subsequent cancerous changes. Conversely, some malignant lesions seen at an early stage may be fallacious for a benign change. ${ }^{11}$

For patients treated within one month of symptom onset, the 5 -year survival rate is $86 \%$, but this decreases to $47 \%$ at seven months after the onset of symptoms. Survival is threatened if treatment occurs after twelve months. ${ }^{30}$ The nonspecific clinical appearance of dysplastic and early malignant lesions further highlights the need to develop objective methodologies for early recognition. ${ }^{31,32}$

Serum diagnostic tests are routinely used in assessment of many systemic disorders. Saliva serves as a substitute for serum as a biologic fluid that can be scrutinized for diagnostic purposes. Saliva meets the demands for an inexpensive, noninvasive, and easy-to-use diagnostic platform. Saliva can be a superior early diagnostic biofluid because of the quantity available and the ease with which specimens are collected, stored, and transported compared to serum and urine. Its nonclotting nature offers an additional advantage by reducing the need for more manipulations. ${ }^{33}$

Home testing kits would further facilitate salivary testing as a diagnostic aid enabling patients, especially those who live far from their treatment centers, to monitor their own health at home. ${ }^{34}$ Early detection will enable up to $90 \%$ of oral cancer patients to be cured, and it facilitates a more cost effective treatment. ${ }^{15}$

The non-invasive process of saliva testing can be an alternative modality to serum testing in diagnosing and determining prognoses in oral cancer. It can also be used in the evaluation of post therapy status. ${ }^{33}$

\section{Recommendations}

- Gaps are clearly seen in our current understanding of the early detection and diagnosis of oral cancer. The following are recommendations for the future course of research activities and target enhancing early detection and diagnosis, and ultimately increasing survival rates of oral cancer patients.

- Recognize the critical need for an interdisciplinary approach towards not only health care, but also research; - Evaluate the outcomes and effectiveness of adaptable screening for high-risk populations, such as those with low socioeconomic status and migrant and indigenous communities;

- Investigate the challenges and initiate examinations of such high-risk populations and consider the use of stateof-the-art methods that would engage non-attendees;

- Evaluate new models of care which include an oral health therapist in oral cancer screening. These therapists are proficient in risk assessment and health promotion, and their expertise is currently underutilized;

- Evaluate the acceptability of new detection technologies and their validity by clinicians;

- Explore the experience and need for support of patients with potential malignant disorder (PMD). Factors such as assisting patients to comply with review appointments, treatment, and ultimately behavior change must be kept on record;

- Scrutinize the functional and suitable customs of raising public awareness of oral cancer and its risk factors;

- Examine medical and dental university programs to ensure that the oral medicine and oral pathology component, particularly in relation to examinations for head and neck cancer, match graduate competencies;

- Investigate to confirm that current professional organizations for oral medicine, oral pathology, and head and neck oncology are doing/could do what they can in public awareness campaigns, practitioner's edification, and policy development to enhance the early detection of oral cancer.

\section{Conclusion}

Informing and educating the public in matters related to well-known risk factors associated with oral cancer is necessary. Reducing the incidence of oral cancer is an aspect of achieving a healthier nation. Community action, capacity-building measures, and raising public awareness could contribute to achieving a significant reduction in incidence. Oral cancer can be detected and diagnosed in its early stages by a thorough 5-minute oral examination. Screening for oral cancer by visual examination is modest, inexpensive, and causes little discomfort. A certain proportion of cancers arise out of premalignant or potentially malignant lesions of the oral mucosa, and early diagnosis and effective treatment of these can reduce the incidence of oral cancer. Initial cancerous lesions are easier to treat than advanced lesions from the perspective of improving a patient's quality of life. Understanding the development and progression of a lesion is key in the quest for early diagnosis and prevention. Early diagnostic techniques are not only beneficial for differentiating normal mucosa from dysplastic or malicious lesions, but they also help in monitoring treatment and potential obstacles. These techniques can facilitate diagnosis in real time, and they are non-invasive. At present, large multicenter trials are necessary to determine the sensitivity and specificity of 
these tests, and to introduce a combination of techniques to assess. These techniques also support to improve their capability to detect and manage potentially malignant and malicious oral lesions.

\section{Authors' Contributions}

All authors contributed equally to this study.

\section{Conflict of Interest Disclosures}

The authors declare that they have no conflicts of interest.

\section{Funding}

None.

\section{References}

1. Lipkin A, VeriMed Healthcare Network. Oral Cancer 2018 [updated 2018; cited 2018]. Available from: https://www.healthcentral.com/encyclopedia/o/oral-cancer.

2. Shin D, Vigneswaran N, Gillenwater A, Richards-Kortum R. Advances in fluorescence imaging techniques to detect oral cancer and its precursors. Future Oncol. 2010;6(7):1143-54. doi: 10.2217/fon.10.79. pmid: 20624126

3. Nitish Grag K, Singhal K. Potentially Oral Malignant Lesion and Oral Cancer and Future Diagnostic Techniques: A Review. Indian J Appl Res. 2013;3(6):421-5.

4. Omar EA. The outline of prognosis and new advances in diagnosis of oral squamous cell carcinoma (OSCC): review of the literature. J Oral Oncol. 2013;3(2):1-13. doi: 10.1155/2013/519312.

5. Du GF, Li CZ, Chen HZ, Chen XM, Xiao Q, Cao ZG, et al. Rose bengal staining in detection of oral precancerous and malignant lesions with colorimetric evaluation: a pilot study. Int J Cancer. 2007;120(9):1958-63. doi: 10.1002/ijc.22467. pmid: 17245698

6. Fedele S. Diagnostic aids in the screening of oral cancer. Head Neck Oncol. 2009;1:5. doi: 10.1186/1758-3284-1-5. pmid: 19284694.

7. Malignant - definition of malignant by The Free Dictionary 2018 [updated 2018; cited 2018]. Available from: https://www.thefreedictionary.com/malignant.

8. World Health Organization. Cancer - World Health Organization 2018 [updated 2018; cited 2014]. Available from: http://www.who.int/news-room/fact-sheets/detail/can cer.

9. Park K. Park's Textbook of Preventive and Social Medicine. Jabalpur: Bhanot Publishers; 2017.

10. Chen YW, Lin JS, Wu CH, Lui MT, Kao SY, Fong Y. Application of in vivo stain of methylene blue as a diagnostic aid in the early detection and screening of oral squamous cell carcinoma and precancer lesions. J Chin Med Assoc. 2007;70(11):497-503. doi: 10.1016/S1726-4901(08)700480. pmid: 18063504.

11. Gupta M, Gupta M, Aggarwal A, Ahuja R. Recent advancements in the diagnosis of oral premalignant and malignant lesions: A comprehensive review. Clin Cancer Invest J. 2013;2(3):181. doi: 10.4103/2278-0513.119249.

12. Masthan KM, Babu NA, Dash KC, Elumalai M. Advanced diagnostic aids in oral cancer. Asian Pac J Cancer Prev. 2012;13(8):3573-6. doi: 10.7314/APJCP.2012.13.8.3573. pmid: 23098535.

13. Sciubba JJ. Improving detection of precancerous and cancerous oral lesions. Computer-assisted analysis of the oral brush biopsy. U.S. Collaborative OralCDx Study Group. J Am Dent Assoc. 1999;130(10):1445-57. pmid: 10570588.

14. Scheifele C, Schmidt-Westhausen AM, Dietrich T, Reichart PA. The sensitivity and specificity of the OralCDx technique: evaluation of 103 cases. Oral Oncol. 2004;40(8):824-8. doi: 10.1016/j.oraloncology.2004.02.004. pmid: 15288838.
15. Ram $\mathrm{S}$, Siar $\mathrm{CH}$. Chemiluminescence as a diagnostic aid in the detection of oral cancer and potentially malignant epithelial lesions. Int J Oral Maxillofac Surg. 2005;34(5):521-7. doi: 10.1016/j.ijom.2004.10.008. pmid: 16053872 .

16. Bhalang K, Suesuwan A, Dhanuthai K, Sannikorn P, Luangjarmekorn L, Swasdison S. The application of acetic acid in the detection of oral squamous cell carcinoma. Oral Surg Oral Med Oral Pathol Oral Radiol Endod. 2008;106(3):371-6. doi: 10.1016/j.tripleo.2008.01.017. pmid: 18547833.

17. Allegra E, Lombardo N, Puzzo L, Garozzo A. The usefulness of toluidine staining as a diagnostic tool for precancerous and cancerous oropharyngeal and oral cavity lesions. Acta Otorhinolaryngol Ital. 2009;29(4):187-90. pmid: 20161875.

18. Nagaraju K, Prasad S, Ashok L. Diagnostic efficiency of toluidine blue with Lugol's iodine in oral premalignant and malignant lesions. Indian J Dent Res. 2010;21(2):218-23. doi: 10.4103/0970-9290.66633. pmid: 20657091.

19. Awan KH, Morgan PR, Warnakulasuriya S. Utility of chemiluminescence (ViziLite) in the detection of oral potentially malignant disorders and benign keratoses. J Oral Pathol Med. 2011;40(7):541-4. doi: 10.1111/j.16000714.2011.01048.x. pmid: 21615500.

20. Awan KH, Morgan PR, Warnakulasuriya S. Evaluation of an autofluorescence based imaging system (VELscope) in the detection of oral potentially malignant disorders and benign keratoses. Oral Oncol. 2011;47(4):274-7. doi: 10.1016/j.oraloncology.2011.02.001. pmid: 21396880.

21. Mehrotra R, Gupta DK. Exciting new advances in oral cancer diagnosis: avenues to early detection. Head Neck Oncol. 2011;3:33. doi: 10.1186/1758-3284-3-33. pmid: 217980 30.

22. Cancela-Rodriguez P, Cerero-Lapiedra R, Esparza-Gomez G, Llamas-Martinez S, Warnakulasuriya $S$. The use of toluidine blue in the detection of pre-malignant and malignant oral lesions. J Oral Pathol Med. 2011;40(4):3004. doi: 10.1111/j.1600-0714.2010.00985.x. pmid: 214264 01.

23. Rana M, Zapf A, Kuehle M, Gellrich NC, Eckardt AM. Clinical evaluation of an autofluorescence diagnostic device for oral cancer detection: a prospective randomized diagnostic study. Eur J Cancer Prev. 2012;21(5):460-6. doi: 10.1097/CEJ.0b013e32834fdb6d. pmid: 22217551.

24. Upadhyay J, Rao NN, Upadhyay RB, Agarwal P. Reliability of toluidine blue vital staining in detection of potentially malignant oral lesions--time to reconsider. Asian Pac J Cancer Prev. 2011;12(7):1757-60. pmid: 22126560.

25. Ujaoney S, Motwani MB, Degwekar S, Wadhwan V, Zade P, Chaudhary $M$, et al. Evaluation of chemiluminescence, toluidine blue and histopathology for detection of high risk oral precancerous lesions: A cross-sectional study. BMC Clin Pathol. 2012;12:6. doi: 10.1186/1472-6890-12-6. pmid: 22410295.

26. Riaz A, Shreedhar B, Kamboj M, Natarajan S. Methylene blue as an early diagnostic marker for oral precancer and cancer. Springerplus. 2013;2(1):95. doi: 10.1186/21931801-2-95. pmid: 23524482.

27. Reddy SP, Ramani P, Nainani P. Confocal microscopy and exfoliative cytology. J Oral Maxillofac Pathol. 2013;17(2):217-21. doi: 10.4103/0973-029X.119746. pmid: 24250082

28. Madbhavi S, Rupnarayan R, SM AM. Efficacy of toluidine blue and brush biopsy in oral lesions. Int J Oral Maxillofac Pathol. 2013;4(1):2-8.

29. Vashisht N, Ravikiran A, Samatha Y, Rao PC, Naik R, Vashisht D. Chemiluminescence and Toluidine Blue as Diagnostic Tools for Detecting Early Stages of Oral Cancer: An invivo Study. J Clin Diagn Res. 2014;8(4):ZC35-8. doi: 10.7860/JCDR/2014/7746.4259. pmid: 24959513.

30. Bhandary S, Bhandary P. Cancer of the oral cavity-a growing concern in the Micronesia: a case report from the Marshall 
Islands. Pac Health Dialog. 2003;10(1):76-8. pmid: 16276948.

31. Scott IS, Odell E, Chatrath P, Morris LS, Davies RJ, Vowler $\mathrm{SL}$, et al. A minimally invasive immunocytochemical approach to early detection of oral squamous cell carcinoma and dysplasia. $\mathrm{Br} J$ Cancer. 2006;94(8):1170-5. doi: 10.1038/sj.bjc.6603066. pmid: 16622441.

32. Ribeiro IP, Barroso L, Marques F, Melo JB, Carreira IM. Early detection and personalized treatment in oral cancer: the impact of omics approaches. Mol Cytogenet. 2016;9:85 doi: 10.1186/s13039-016-0293-1. pmid: 27895714.

33. Koneru S, Tanikonda R. Salivaomics - A promising future in early diagnosis of dental diseases. Dent Res J (Isfahan). 2014;11(1):11-5. pmid: 24688554.

34. Pujari M, Bahirwani S, Balaji P, Kaul R, Shah B, Daryani D, et al. Oral fluid nanosensor test: saliva as a diagnostic tool for oral health. J Calif Dent Assoc. 2012;40(9):733-6. pmid: 23097828. 